\title{
Metastatic Breast Cancer Survival in Pointe Noire: Analysis of 30 Cases
}

\author{
C. F. S. Ngatali ${ }^{*}$, A. F. Bolenga Liboko², M. L. Eouani ${ }^{3}$, L. M. A. Boumba ${ }^{4}$, P. E. G. Sounga Bandzouzi ${ }^{5}$, \\ E. Ndounga' ${ }^{2}$ Y. Mabila'2, D. Moukassa', J. B. Nkoua-Mbon ${ }^{2}$
}

${ }^{1}$ Department of Oncology and Internal Medicine, Loandjili General Hospital, Pointe Noire, Congo

${ }^{2}$ Medical Oncology Department, CHU-Brazzaville, Brazzaville, Congo

${ }^{3}$ Department of Gynecology, Loandjili General Hospital, Pointe Noire, Congo

${ }^{4}$ Laboratoire d'Anatomie Pathologie, Loandjili General Hospital, Pointe Noire, Congo

${ }^{5}$ Departement of Neurology, Loandjili General Hospital, Pointe Noire, Congo

${ }^{6}$ Hospital General Edith Lucie Bongo, Oyo, Congo

Email: *christianngatali2003@yahoo.fr

\begin{abstract}
How to cite this paper: Ngatali, C.F.S., Liboko, A.F.B., Eouani, M.L., Boumba, L.M.A., Bandzouzi, P.E.G.S., Ndounga, E., Mabila, Y., Moukassa, D. and Nkoua-Mbon, J.B. (2019) Metastatic Breast Cancer Survival in Pointe Noire: Analysis of 30 Cases. Open Journal ot Pathology, 9, 86-99.

https://doi.org/10.4236/ojpathology.2019.94 010
\end{abstract}

Received: July 5, 2019

Accepted: September 27, 2019

Published: September 30, 2019

Copyright (๑) 2019 by author(s) and Scientific Research Publishing Inc. This work is licensed under the Creative Commons Attribution-NonCommercial International License (CC BY-NC 4.0). http://creativecommons.org/licenses/by-nc/4.0/ (c) (i) \& Open Access

\section{Abstract}

Introduction: Breast cancer is the leading cancer and the leading cause of cancer death in women worldwide. About $5 \%$ to $10 \%$ of breast cancer patients present with metastases. While the 5-year survival of patients with local breast cancer varies around $98.8 \%$, this survival rate drops to around $26.3 \%$ for metastatic patients. The objective of this study was to determine the survival of patients with metastatic breast cancer in resource-limited settings. Patients and Methods: This was a cross-sectional descriptive study that took place in the Cancer Department of the General Hospital of Loandjili in Pointe Noire during the period from January 1, 2013 to December 31, 2018, for duration of 6 years. 30 records of patients over 18 years of age and with histological evidence who received at least 3 courses of chemotherapy were collected. The variables studied were: age, level of education, socio-economic level, menopausal status, history, WHO status, menopausal status, tumor size, histological type, tumor location, the type of treatment and survival. Survival was calculated by Kaplan Meier method. Fisher's exact test was used to search for correlation between variables. Results: The average age was $52.62 \pm 10.96$ years old. The extremes were 33 years and 75 years old. The most represented level of education was the primary level in $67 \%$ of cases. The majority of patients had low socioeconomic status in $50 \%$ of cases. The patients were menopausal in $57 \%$ of cases. The antecedents of cancer were present in $13 \%$ of cases. $50 \%$ of patients had a WHO status performance at 2 . The tumor size was greater than $2 \mathrm{~cm}$ in $77 \%$ of cases. The most represented histological type was invasive ductal carcinoma in $93 \%$ of cases. The most represented histological grade was Scharff grade III Richardson bloom in $80 \%$ of cases. The 
most represented metastatic localization was pulmonary in $33 \%$ of cases. The metastatic localizations were unique in $47 \%$ of cases and multiple in $53 \%$ of cases. Anthracycline-based chemotherapy was more used in $53 \%$ of cases. Bivariate analysis revealed a correlation between tumor size and number of metastases, $\mathrm{p}<0.05$. The mean patient follow-up time was $22 \pm 15.45$ months. The median overall survival was 35.35 months. Brain metastases (18.2 months) had a poor prognosis compared to liver metastases (25.4 months). The median survival of pulmonary metastases was 36.5 months, $\mathrm{p}>$ 0.05. Patients treated with anthracyclines were greater than that of patients treated with taxanes in combination was 26.48 months, $\mathrm{p}>0.05$. Conclusion: Metastatic breast cancer remains an incurable disease, its survival remains low despite diagnostic and therapeutic advances that remain difficult to access for our resource-poor developing countries. Patients are treated with conventional chemotherapy (anthracyclines and taxanes). The most common metastases are respectively pulmonary, hepatic and cerebral in our context.

\section{Keywords}

Breast Cancer, Metastatic, Survival, Pointe Noire, Congo

\section{Introduction}

Breast cancer is the leading cancer and the leading cause of cancer death in women worldwide [1] [2]. This condition was diagnosed in women at a frequency of $24.2 \%$ and was responsible for nearly $15 \%$ of deaths in 2018 [2]. This cancer is also the first diagnosed and the leading cause of cancer deaths in women in developing countries [1]. In these resource-limited settings, breast cancer is often diagnosed at advanced stages and is responsible for poor prognosis [3]. The last two decades have seen major advances in screening, biomolecular diagnosis and therapeutic breast cancer. Despite these advances, metastatic breast cancer remains an incurable disease, therefore the ultimate goal is to prolong overall survival and improve quality of life [4]. Breast cancer can invade the liver, lungs, bones, the brain, the skin and other organs [5] [6] [7]. The metastatic breast cancer is divided in two, on the one hand the primary metastatic cancer known as Novo or synchronous, whose diagnosis of metastasis is made same time as the primary tumor, on the other hand there is secondary metastatic breast cancer or metachronous whose diagnosis of metastasis is made months or years after the diagnosis of the primary tumor [8] [9] [10]. About 5\% to $10 \%$ of breast cancer patients present with de novo metastases [4] [11] [12] [13]. However, 20\% to 50\% of breast cancer patients have secondary or metachronous metastases [14] [15]. While the 5 -year survival of patients with local breast cancer varies around 98.8\%, this survival rate drops to around $26.3 \%$ for metastatic patients. In Congo, few studies have been done on the subject. Thus our study aimed to determine the survival of patients with metastatic breast cancer in resource-limited settings. 


\section{Patients and Methods}

This was a cross-sectional descriptive study that took place in the Cancer Department of the General Hospital of Loandjili in Pointe Noire during the period from January 1, 2013 to December 31, 2018, for duration of 6 years. Have been included in our study: all patients over 18 years old; all patients with a complete file that is to say with a histological diagnosis and an extension assessment performed through an abdominal chest CT scan and/or an ultrasound or chest x-ray; all patients diagnosed with primary or de novo breast cancer (synchronous) and secondary or metachronous breast cancer; all patients who received at least 3 courses of chemotherapy [chemotherapy was based on anthracyclines (FAC protocol $=5$ fluorouracil, dose $500 \mathrm{mg} / \mathrm{m}^{2}$, doxorubicin $50 \mathrm{mg} / \mathrm{m}^{2}$ cyclophosphamide $500 \mathrm{mg} / \mathrm{m}^{2}$ ) and taxanes (docetaxel protocol dose $100 \mathrm{mg} / \mathrm{m}^{2}$ )]; all patients with no histological diagnosis were excluded from our study; all men with breast cancer. The variables studied were: Sociodemographic parameters: age, level of education, socio-economic level; Clinical parameters: WHO status performance, menopausal status, tumor size, number of lymph node involvement, metastatic localization of metastasis, number of metastases; Histological type and histological grade; The type of treatment; The survival. The data collection was done from a survey sheet, comprising the different variables studied.

Bivariate analysis was done between size and number of metastasis. The data entry was made from the Excel version 2016 software. Qualitative variables were represented in numbers and percentages. Quantitative variables were represented in numbers and on average. Statistical analysis and data processing were performed by the Excel 2016 software and graphpad Prism version 7 software. The statistical test used was Fisher's exact test for finding correlation between variables. Survival was calculated by Kaplan Meier method. The initial date was the date of diagnosis of metastasis; the point date was the end date of the study. The final event was the occurrence of death. Patients were followed throughout the study period, from January 1, 2013 to December 31, 2018, for a period of 6 years. The comparison of the curves was made by the logrank test. The results were statistically significant for $\mathrm{p}<5 \%$.

\section{Results}

At the end of our study, 30 files of metastatic breast cancer patients fulfilling the criteria of inclusions were collected. The average age was $52.62 \pm 10.96$ years old. The extremes were 33 years and 75 years old. The most represented age group was the age group from 53 to 62 in 33\%, followed by the age group from 43 to 52 (Table 1). The highest level of education was the primary level in $67 \%$ of cases followed by the higher level of education in $20 \%$ and the secondary level in $13 \%$ of cases (Table 2). The majority of patients had a low socio-economic level in $50 \%$ of cases; the intermediate socio-economic level and higher were represented in $37 \%$ and $17 \%$ of cases respectively (Table 3). Patients were menopausal status in $57 \%$ of cases (Table 4). We found a history of cancer in $13 \%$ of cases (Table 5). $50 \%$ of patients had a WHO status performance of $2 ; 40 \%$ of patients had a 
performance at $1,7 \%$ of patients had at 0 and $3 \%$ of patients had at 1 (Table 6). Tumor size was greater than $2 \mathrm{~cm}$ in $77 \%$ of cases and was less than $2 \mathrm{~cm}$ in $23 \%$ of cases (Table 7). The patients had respectively two nodes invaded in $53 \%$ of cases and 3 nodes in $27 \%$ of cases (Table 8). The most represented histological type was invasive ductal carcinoma in $87 \%$ of cases, lobular carcinoma in $10 \%$ of cases and a 3\% breast sarcoma (Figure 1). The most represented histological grade was grade III of Scharff bloom Richardson in $80 \%$ of cases followed respectively by grade II and grade I with respective percentages of $10 \%$ and $5 \%$. Metastatic localization the most represented was that of the lungs in $33 \%$ of cases (Table 9). The metastatic localization was unique in $47 \%$ of cases and multiple in $53 \%$ of cases (Table 10). The most widely used chemotherapies were chemotherapy-based anthracyclines in 53\% and taxan-based chemotherapy alone or in combination with anthracyclines in $34 \%$ of cases. Only one patient had received targeted therapy (Table 11). Bivariate analysis found a correlation between tumor size and number of metastases, the result was statistically significant (Table 12). The mean patient follow-up time was $22 \pm 15.45$ months. The median overall survival was 35.35 months (Figure 2). The median survival of patients with lung, liver and brain metastases, with the lungs and liver (lungs + liver) associated with the lungs and lymph nodes (lungs + lymph nodes), was respectively 36.5 months, 25.4 months, 18.26 months, 24.3 months, 37.5 months. There was no statistically significant difference (Figure 3 ). The survival of patients treated with anthracyclines was 36.35 months that of Patients treated with Texan was 26.48 months, the result was not statistically significant (Figure 4).

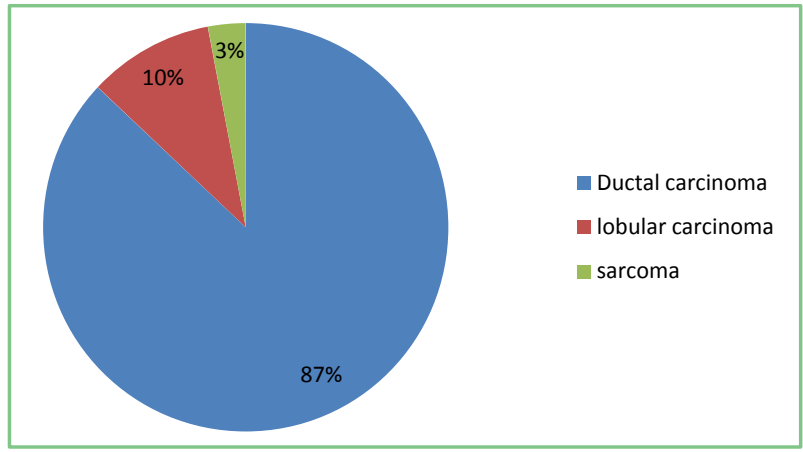

Figure 1. Distribution of patients by histological type.

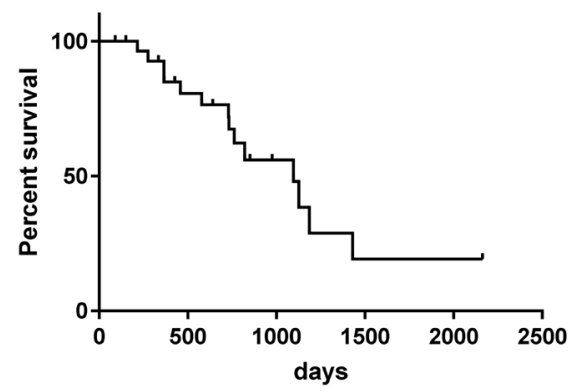

Figure 2. Representation of the survival curve of patients with metastatic breast cancer. 


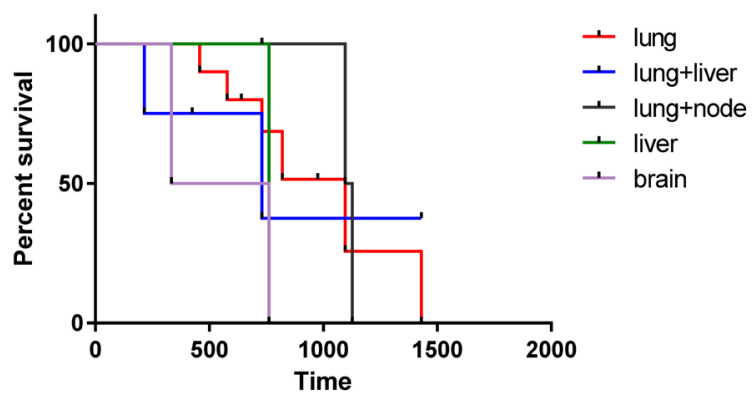

Figure 3. Comparison of survival curves versus metastatic localization. $\mathrm{P}>0.05$ statistically insignificant.

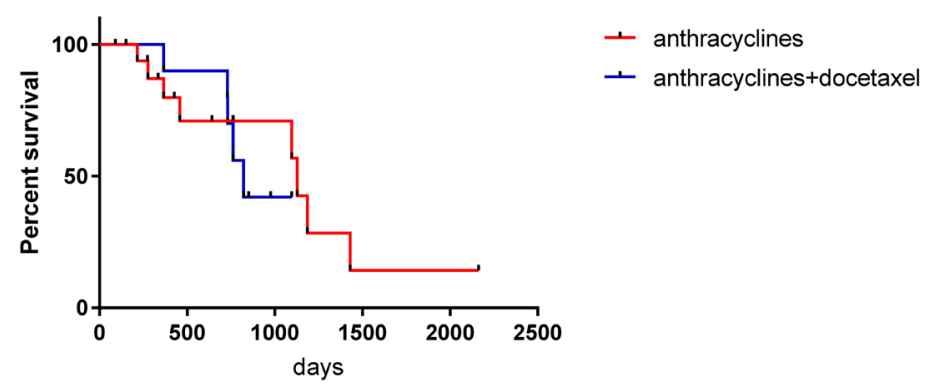

Figure 4. Comparison of survival curves by type of treatment. $\mathrm{P}>0.05$ non significant results.

Table 1. Distribution of patients according to group age.

\begin{tabular}{ccc}
\hline Group age & Number & Percentage \\
\hline $33-42$ & 5 & $17 \%$ \\
$43-52$ & 9 & $30 \%$ \\
$53-62$ & 10 & $33 \%$ \\
$63-72$ & 4 & $13 \%$ \\
$73-82$ & 2 & $7 \%$ \\
Total & 30 & $100 \%$ \\
\hline
\end{tabular}

Table 2. Distribition of patients according to study level.

\begin{tabular}{ccc}
\hline Study level & Number & Percentage \\
\hline Primairy & 20 & $67 \%$ \\
Secondary & 4 & $13 \%$ \\
Superior & 6 & $20 \%$ \\
Total & 30 & $100 \%$ \\
\hline
\end{tabular}

Table 3. Distribution of patients according to socioeconomic level.

\begin{tabular}{ccc}
\hline Socioeconomic level & Number & Percentage \\
\hline Low & 15 & $50 \%$ \\
High & 11 & $37 \%$ \\
Intermediate & 4 & $13 \%$ \\
Total & 30 & $100 \%$ \\
\hline
\end{tabular}


Table 4. Distribution of patients according to menopausal status.

\begin{tabular}{ccc}
\hline $\begin{array}{c}\text { Menopausal } \\
\text { status }\end{array}$ & Number & Percentage \\
\hline No & 13 & $43 \%$ \\
yes & 17 & $57 \%$ \\
Total & 30 & $100 \%$ \\
\hline
\end{tabular}

Table 5. Distribution of patients according to cancer histoty.

\begin{tabular}{ccc}
\hline $\begin{array}{c}\text { Cancer } \\
\text { history }\end{array}$ & Number & Percentage \\
\hline No & 26 & $87 \%$ \\
yes & 4 & $13 \%$ \\
Total & 30 & $100 \%$ \\
\hline
\end{tabular}

Table 6. Distribution of patients according to performance status of WHO.

\begin{tabular}{ccc}
\hline $\begin{array}{c}\text { Performance } \\
\text { status }\end{array}$ & Number & Percentage \\
\hline 0 & 2 & $7 \%$ \\
1 & 12 & $40 \%$ \\
2 & 15 & $50 \%$ \\
3 & 1 & $3 \%$ \\
Total & 30 & $100 \%$ \\
\hline
\end{tabular}

Table 7. Distribution of patients according to tumor size.

\begin{tabular}{ccc}
$\begin{array}{c}\text { Tumor } \\
\text { size }\end{array}$ & Number & Percentage \\
\hline $2 \mathrm{~cm}$ & 7 & $23 \%$ \\
$>2 \mathrm{~cm}$ & 23 & $77 \%$ \\
Total & 30 & $100 \%$ \\
\hline
\end{tabular}

Table 8. Distribution of patients according to the number of invade nodes.

\begin{tabular}{ccc}
$\begin{array}{c}\text { Nodes } \\
\text { number }\end{array}$ & Effective & Percentage \\
\hline 0 & 2 & $7 \%$ \\
1 & 4 & $13 \%$ \\
2 & 16 & $53 \%$ \\
3 & 8 & $27 \%$ \\
Total & 30 & $100 \%$ \\
\hline
\end{tabular}


Table 9. Distribution of patients according to metastatic localization.

\begin{tabular}{ccc}
\hline Metastatic localization & Number & Percentage \\
\hline bone + foie & 2 & $7 \%$ \\
brain & 2 & $7 \%$ \\
liver & 2 & $7 \%$ \\
lung & 10 & $33 \%$ \\
lung + node + rachis & 3 & $10 \%$ \\
lung + liver & 5 & $17 \%$ \\
lung + nodes & 2 & $7 \%$ \\
Lung + bone + liver & 4 & $13 \%$ \\
Total & 30 & $100 \%$
\end{tabular}

Table 10. Distribution of patients according to number of metastases.

\begin{tabular}{ccc}
\hline Metastases number & Number & Percentage \\
\hline Multiple & 16 & $53 \%$ \\
Unique & 14 & $47 \%$ \\
Total & 30 & $100 \%$ \\
\hline
\end{tabular}

Table 11. Distribution of patients according to treatment.

\begin{tabular}{ccc}
\hline Chemotherapy type & Number & Percentage \\
Fac & 17 & $53 \%$ \\
fac + taxotere & 11 & $34 \%$ \\
taxotere & 2 & $6 \%$ \\
taxotere + avastin & 1 & $3 \%$ \\
capecitabine & 1 & $3 \%$ \\
Total & 32 & $100 \%$
\end{tabular}

Table 12. Distribution of patients according to tumor size and number of metastases

\begin{tabular}{cccc}
\hline \multicolumn{4}{c}{ Metastases Number } \\
\hline Tumor Size & Unique & Multiple & Total \\
\hline$<2 \mathrm{~cm}$ & 6 & 1 & 7 \\
$>2 \mathrm{~cm}$ & 8 & 15 & 23 \\
Total & 14 & 16 & 30 \\
\hline
\end{tabular}

$\mathrm{P}<0.05$ results statistically significant.

The histological grade most represented was grade III of Scharff bloom Richardson in $80 \%$ of cases followed respectively by grade II and grade I with respective percentages of $10 \%$ and $5 \%$. 


\section{Discussion}

At the end of our study, which took place in the Oncology Department of Loandjili General Hospital in Pointe Noire, we collected 30 cases of women with metastatic breast cancer who met the inclusion criteria of our study. The mean age in our study was $52.62 \pm 10.96$ years with extremes of 33 years and 75 years. This average age and these extremes are close to those found in the literature [7] [16]. In contrast to the relatively young average age in our study, other studies have found a mean age of 61 years [5] [8]. The most represented age group in our study was the 53 -year-old angel slice at age 62 in $33 \%$ of cases. These results are in agreement with the literature which explains the presence of metastases during breast cancer, because of the age, the menopause would be a factor favoring the occurrence of metastases as we can observe in our study, that the majority of patients were menopausal in $57 \%$ of cases. [16] [17]. The majority of patients in our study had a primary education level in $67 \%$ of cases. In the literature the level of study was higher. Although there is no cancer control program that should facilitate access to information on cancer disease but also screening, the level of primary education is a factor contributing to the lack of knowledge about cancer. The cancerous disease, thus allows time for it to spread in several organs. In the Guié et al. study in Côte d'Ivoire, only $21 \%$ of women over 50 had benefited from breast cancer screening [18]. The socioeconomic level was low in our study and in the majority of African studies since developing countries are poor in the majority of cases [7] [18] [19]. In Africa the management of the cancerous disease is excessively excessive and is the responsibility of the patient and/or the family of the patient, in addition there is no health insurance, the whole making difficult the accessibility specialty services of the disease. The patients were menopausal in the majority (57\%) of cases in our study. One study also reports this predominance of postmenopausal women in $77.6 \%$ of cases [6]. The antecedents of breast cancer reported in $13 \%$ of patients in our study were similar to those of Athanasios kotsakis et al. in Greece [6]. The most represented WHO status performance was 0 to 2 in the majority of cases. This result is consistent with the literature [6]. Patients with a tumor size greater than $2 \mathrm{~cm}$, ganglion number greater than two, histological grade III, were the most represented in $77 \%$ of cases, $60 \%$ of cases and $60 \%$ of cases in our study respectively. These results corroborate those of the literature [5] [18] [20]. Tumor size is a prognostic factor for breast cancers also associated with lymph node involvement and histological grade. As all these prognostic factors increase, the risk of metastases is high [12]. Approximately $25 \%$ to $30 \%$ of patients without lymph node involvement and tumor size greater than $2 \mathrm{~cm}$ will develop recurrence in 20 years [21]. Only $2 \%$ of patients with a tumor size of less than $1 \mathrm{~cm}$ die within 5 years of diagnosis [22]. The number of lymph nodes affected has been correlated with metastatic risk in the literature [23]. Although they are determining factors for the local treatment of breast cancer, these prognostic factors are also determinants for the initiation of adjuvant or complementary treatment. The most represented histological type was invasive ductal carcinoma 
in $87 \%$ of cases. This result corroborates to the literature [5] [18] [24] [25]. The risk of developing metastases according to the histological type is practically the same, which explains the same treatment between invasive ductal carcinoma and invasive lobular carcinoma [12]. In our study, visceral metastases were most represented by pulmonary metastases in $30 \%$ of cases and hepatic metastases in $10 \%$ of cases. Bone metastases were represented in association with other metastases in two cases. These results do not corroborate with those of some authors of the literature. Indeed several authors have described the predominance of bone metastases in their series [5] [7] [20], this could probably be explained by an underestimation of bone metastases due to the lack of other balance sheet examinations, such as bone scans and pet scan that are not available in our limited resource context. On the other hand, one study reported the same pulmonary prevalence as in our study [25]. The multiple metastases were the most represented in our study contrary to the literature that reported predominance. Metastatic breast cancer is incurable, under these conditions the goal of treatment is the improvement of the quality of life and the prolongation of survival. Nowadays the advent of targeted therapies and immunotherapy combined with conventional chemotherapy has helped to achieve the goal of these treatments that of improving the quality of life and prolonging survival. Thus, in our study, patients received anthracycline chemotherapy in $53 \%$ of cases, continuously or sequentially associated with taxanes in $34 \%$ of cases. These results corroborate those of the literature [5] [20] [25]. The absence of health insurance, the high cost of targeted therapies was a limiting factor in the use of these, so only one patient was able to benefit from targeted therapies. The absence of immunohistochemistry for the detection of hormone receptors made it impossible to use hormonal treatment. In our study we observed a positive correlation between tumor size and number of metastases. The number of metastases increased with tumor size. Size is a prognostic factor for breast cancer.

Although small in size with a sample of 30 patients representing approximately the female population of Pointe Noire suffering from cancer and being a hospital study, our study suffered from a few limitations. Indeed in terms of survival, several studies were based on bimolecular characteristics that could not be realized in our context of resource-limited countries. It was the hormonal status, the expression of the Her 2 receptor, which have been necessary elements for the establishment of survival comparisons, especially as they are prognostic and predictive factors apart from other factors such as the performance status of WHO. The hormonal status and expression of Her 2 receptors are still widely used in the therapeutic decision of breast cancer [26] [27] [28] [29]. Our study was based on the median of overall survival, the median survival of patients according to metastatic localization (lungs, liver, lungs + liver, lungs + node and brain). Thus, the median of overall survival in our study was 35.35 months. These results corroborate those in the literature [5] [25]. The median overall survival of patients with metastases to the lungs, liver, lungs + liver, lungs + ganglion, brain in our study were respectively 27.4 months, 25.4 months, 23.3 months, 
36.5 months, 18.2 months.

Brain metastases were those with the lowest median survival. Indeed, brain metastases are difficult to access to cytotoxic treatments because of the bloodbrain barrier that prevents the passage of anticancer drugs. Moreover, no patient has been able to benefit from a specific local treatment (surgery and radiotherapy). The liver is a common site of metastasis of breast cancer, with bone and lung [30] [31] [32]. Liver metastases in breast cancer patients are a prognostic factor independent of other risk factors [15] [33], since the median survival of patients with breast cancer with hepatic metastasis varies from 4.8 to 15 months [34] [35] [36] [37] [38]. In contrast, breast cancer patients with lung or bone metastases have median survival rates of 9 to 27.4 months [37] [38] and 16.3 to 56 months [37] [39] [40], respectively. The survival of breast cancer patients with cerebral metastases was estimated in the literature between 4 and 16 months [41] [42] [43] [44]. This rate is close to that of our study which was 18.6 months. The median overall survival of anthracycline-treated patients was 36.35 months, while that of taxane and anthracycline-treated patients was 26.48 months. These results were statistically insignificant. In the literature, associations with texanes are superior to those without taxanes [45].

\section{Conclusion}

Metastatic breast cancer remains an incurable disease, the goal of its treatment is to prolong survival and improve quality of life. Despite the limitations of our study, the survival of patients with metastatic breast cancer remains low. The various advances in diagnosis and therapeutics of recent years are currently difficult to access in developing countries with limited resources. Anthracycline-based chemotherapy remains the basis of treatment. The most frequent metastatic sites are pulmonary, hepatic and cerebral. However, studies with a larger sample are needed to support its observations in our context with limited resources.

\section{Conflicts of Interest}

The authors declare no conflicts of interest regarding the publication of this paper.

\section{References}

[1] Jemal, A., Bray, F., Center, M.M., et al. (2011) Global Cancer Statistics. CA: $A$ Cancer Journal for Clinicians, 61, 69-90. https://doi.org/10.3322/caac.20107

[2] Bray, F., Ferlay, J., Soerjomataram, I., Siegel, R.L., Torre, L.A. and Jemal, A. (2018) Global Cancer Statistics: GLOBOCAN Estimates of Incidence and Mortality Worldwide for 36 Cancers in 185 Countries. CA: A Cancer Journal for Clinicians, 68, 394-424. https://doi.org/10.3322/caac.21492

[3] Lauby-Secretan, B., Scoccianti, C., Loomis, D., Benbrahim-Tallaa, L., Bouvard, V., Bianchini, F., Straif, K. and International Agency for Research on Cancer Handbook Working Group (2015) Breast-Cancer Screening-Viewpoint of the IARC Working Group. The New England Journal of Medicine, 372, 2353-2358. 
https://doi.org/10.1056/NEJMsr1504363

[4] Dafni, U., Grimani, I., Xyrafas, A., Eleftheraki, A.G. and Fountzilas, G. (2010) Fifteen-Year Trends in Metastatic Breast Cancer Survival in Greece. Breast Cancer Research and Treatment, 119, 621-631. https://doi.org/10.1007/s10549-009-0630-8

[5] Barinoff, J., Heitz, F., Kuemmel, S., Dittmer, C., Hils, R., Lorenz-Salehi, F., Traut, A. and Bois, A. (2013) Improvement of Survival in Patient with Primary Metastatic Breast Cancer over a 10-Year Periode: Prospective Analyses Based on Individual Patient Date from a Multicenter Data Bank. Journal of Cancer Therapy, 4, 1306-1312. https://doi.org/10.4236/jct.2013.48154

[6] Kotsakis, A., Ardavanis, A., Koumakis, G., Samanthas, E., Psyrri, A. and Papadimitriou, C. (2019) Epidemiological Characteristics, Clinical Outcomes and Management Patterns of Metastatic Breast Cancer Patients in Routine Clinical Care Settings of Greece: Results from the EMERGE Multicenter Retrospective Chart Review Study. BMC Cancer, 19, 88. https://doi.org/10.1186/s12885-019-5301-5

[7] Dia, J., Saki, C., Mouhideen, O., Bohoussou, E., Touré, M., Okon, G., Guié, P. and Anongba, S. (2017) Epidemiological Aspects of Metastatic Relapse of Breast Cancer in an African Context. Open Journal of Obstetrics and Gynecology, 7, 552-561. https://doi.org/10.4236/ojog.2017.75058

[8] Smigal, C., Jemal, A., Ward, E., et al. (2006) Trends in Breast Cancer by Race and Ethnicity: Update 2006. CA: A Cancer Journal for Clinicians, 56, 168-183. https://doi.org/10.3322/canjclin.56.3.168

[9] Brewster, A.M., Hortobagi, G.N., Brogilo, K.R., et al. (2008) Residual Risk of Breast Cancer Recurrence 5 Years after Adjuvant Therapy. Journal of the National Cancer Institute, 100, 1179-1183. https://doi.org/10.1093/jnci/djn233

[10] Schon, D., Bertz, J., Gorsch, B., Haberland, J. and Kurth, B.-M. (2004) Die Dachdokumentation Krebs. Gesundheitsbl-Gesundheitsforsch-Gesundheitsschutz, 47, 429-436. https://doi.org/10.1007/s00103-004-0830-7

[11] Surveillance Epidemiology and End Results Program (2005) 1973-2002. Division of Cancer Control and Population Science, National Cancer Institute. https://seer.cancer.gov

[12] Rugo, H.S., Majure, M., Dragun, A., Buxton, M. and Esserman, L. (2017) Neoplasms of Breast. In: Bast Jr., R.C., et al., Eds., Holland-Frei Cancer Medicine, 9th Edition, Wiley-Blackwell, Hoboken, NJ, 1368-1438.

[13] Gnerlich, J., Jeffe, D.B., Deshpande, A.D., Beers, C., Zander, C. and Margenthaler, J.A. (2007) Surgical Removal of the Primary Tumor Increases Overal Survival in patients with Metastatic Breast Cancer: Analysis of the 1998-2003 SEER Data. Annals of Surgical Oncology, 14, 2187-2194. https://doi.org/10.1245/s10434-007-9438-0

[14] Lu, J., Steeg, P.S., Price, J.E., Krishnamurthy, S., Mani, S.A., Reuben, J., et al. (2009) Breast Cancer Metastasis: Challenges and Opportunities. Cancer Research, 69, 49514953. https://doi.org/10.1158/0008-5472.CAN-09-0099

[15] Bonotto, M., Gerratana, L., Poletto, E., Driol, P., Giangreco, M., Russo, S., et al. (2014) Measures of Outcome in Metastatic Breast Cancer: Insights from a Real-World Scenario. Oncologist, 19, 608-615. https://doi.org/10.1634/theoncologist.2014-0002

[16] Chevallier, B., Heintzman, F. and Mosseri, V. (1989) Quels sont les facteurs pronostics du cancer du sein opérable sans envahissement ganglionnaire axillaire histologique? Résultats d'une analyse uni et multifactorielle. Bulletin du Cancer, 76, 51-60.

[17] De La Rochefordière, A., Asslain, B. and Campana, F. (1993) Age Prognostic Factor in Premenopausal Breast Carcinoma. The Lancet, 341, 1039-1043. 
https://doi.org/10.1016/0140-6736(93)92407-K

[18] Djanhan, L.E., Dia, J.M., Mian, B., Oyelade, M., Diallo, A., Guié, P. and Anongba, S. (2017) Occurrence Delays of Metastatic Relapses of Breast Cancers Treated at University Hospital of Treichville (Abidjan-Cote d'Ivoire). Journal of Cancer Therapy, 8, 924-932. https://doi.org/10.4236/jct.2017.811081

[19] Toure, M., Nguessan, E., Bambara, A.T., Kouassi, Y.K.K., Dia, J.M.L. and Adoubi, I. (2013) Factors Linked to Late Diagnosis in Breast Cancer in Sub-Saharan Africa: Case of Cote D’Ivoire. Gynécologie Obstétrique et Fertilité, 41, 696-700. https://doi.org/10.1016/j.gyobfe.2013.08.019

[20] Korpela, J., Mali, P., Kaljonen, A. and Salminen, E. (2011) Quality of Life of Patients with Metastatic Breast Cancer Treated with Epirubicin and Docetaxel. International Journal of Clinical Medicine, 2, 346-351. https://doi.org/10.4236/ijcm.2011.23060

[21] Rosen, P.P., Groshen, S., Kinne, D.W. and Norton, L. (1993) Factors Influencing Prognosis in Node Negative Breast Carcinoma: Analysis of 767 T1N0M0/T2N0M0 Patients with Long Term Follow-Up. Journal of Clinical Oncology, 11, 2090-2100. https://doi.org/10.1200/JCO.1993.11.11.2090

[22] Hanrahan, E.O., Gonzalez-Angulo, A.M., Giordano, S.H., et al. (2007) Overall Survival and Cause-Specific Mortality of Patients with Stage T1a,bN0M0 Breast Carcinoma. Journal of Clinical Oncology, 25, 4952-4960. https://doi.org/10.1200/JCO.2006.08.0499

[23] Nemoto, T., Vana, J., Bedwani, R.N., et al. (1980) Management and Survival of Female Breast Cancer: Results of a National Survey by the American College of Surgeons. Cancer, 45, 2917-2924.

https://doi.org/10.1002/1097-0142(19800615)45:12<2917::AID-CNCR2820451203> 3.0.CO;2-M

[24] Hammoud, H., Saleh, J., Bachour, M. and Salamoon, M. (2014) Serum Caspase-3 and Caspase-7 as Predictive Factors of Response in Locally Advanced and Metastatic Breast Carcinoma. Journal of Cancer Therapy, 5, 584-590. https://doi.org/10.4236/jct.2014.56067

[25] Gogia, A., Deo, S.V.S., Sharma, D., Thulkar, S., Kumar, R., Malik, P.S. and Mathur, S. (2019) Clinicopathologic Characteristics and Treatment Outcomes of Patients with up-Front Metastatic Breast Cancer: Single-Center Experience in India. Journal of Global Oncology, 5, 1-9. https://doi.org/10.1200/JGO.18.00265

[26] National Comprehensive Cancer Network (2016) NCCN Clinical Practice Guidelines in Oncology: Breast Cancer, Version 2. http://www.nccn.com

[27] Cardoso, F., Costa, A., Senkus, E., Aapro, M., André, F., Barrios, C.H., et al. (2017) 3rd ESO-ESMO International Consensus Guidelines for Advanced Breast Cancer (ABC 3). Annals of Oncology, 28, 16-33.

[28] Colombo, P.E., Milanezi, F., Weigelt, B. and Reis-Filho, J.S. (2011) Microarrays in the 2010s: The Contribution of Microarray-Based Gene Expression Profiling to Breast Cancer Classification, Prognostication and Prediction. Breast Cancer Research, 13, 212. https://doi.org/10.1186/bcr2890

[29] Parise, C.A. and Caggiano, V. (2014) Breast Cancer Survival Defined by the ER/PR/HER2 Subtypes and a Surrogate Classification According to Tumor Grade and Immunohistochemical Biomarkers. Journal of Cancer Epidemiology, 2014, Article ID: 469251. https://doi.org/10.1155/2014/469251

[30] Hess, K.R., et al. (2006) Metastatic Patterns in Adenocarcinoma. Cancer, 106, 1624-1633. https://doi.org/10.1002/cncr.21778 
[31] Berman, A.T., Thukral, A.D., Hwang, W.T., Solin, L.J. and Vapiwala, N. (2013) Incidence and Patterns of Distant Metastases for Patients with Early-Stage Breast Cancer after Breast Conservation Treatment. Clinical Breast Cancer, 13, 88-94. https://doi.org/10.1016/j.clbc.2012.11.001

[32] Savci-Heijink, C.D., et al. (2015) Retrospective Analysis of Metastatic Behaviour of Breast Cancer Subtypes. Breast Cancer Research and Treatment, 150, 547-557. https://doi.org/10.1007/s10549-015-3352-0

[33] Gerratana, L., et al. (2015) Pattern of Metastasis and Outcome in Patients with Breast Cancer. Clinical \& Experimental Metastasis, 32, 125-133. https://doi.org/10.1007/s10585-015-9697-2

[34] Wyld, L., et al. (2003) Prognostic Factors for Patients with Hepatic Metastases from Breast Cancer. British Journal of Cancer, 89, 284-290. https://doi.org/10.1038/sj.bjc.6601038

[35] Tarhan, M.O., et al. (2013) The Clinicopathological Evaluation of the Breast Cancer Patients with Brain Metastases: Predictors of Survival. Clinical \& Experimental Metastasis, 30, 201-213. https://doi.org/10.1007/s10585-012-9528-7

[36] Tseng, L.M., et al. (2013) Distant Metastasis in Triple-Negative Breast Cancer. Neoplasma, 60, 290-294. https://doi.org/10.4149/neo_2013_038

[37] Liu, X.H., Man, Y.N., Cao, R., Liu, C. and Wu, X.Z. (2014) Individualized Chemotherapy Based on Organ Selectivity: A Retrospective Study of Vinorelbine and Capecitabine for Patients with Metastatic Breast Cancer. Current Medical Research and Opinion, 30, 1017-1024. https://doi.org/10.1185/03007995.2014.895310

[38] Ahn, S.G., et al. (2013) Prognostic Factors for Patients with Bone-Only Metastasis in Breast Cancer. Yonsei Medical Journal, 54, 1168-1177. https://doi.org/10.3349/ymj.2013.54.5.1168

[39] Purushotham, A., et al. (2014) Age at Diagnosis and Distant Metastasis in Breast Cancer-A Surprising Inverse Relationship. European Journal of Cancer, 50, 1697-1705. https://doi.org/10.1016/j.ejca.2014.04.002

[40] Karimi, A., Delpisheh, A., Sayehmiri, K., Saboori, H. and Rahimi, E. (2014) Predictive Factors of Survival Time of Breast Cancer in Kurdistan Province of Iran between 2006-2014: A Cox Regression Approach. Asian Pacific Journal of Cancer Prevention, 15, 8483-8488. https://doi.org/10.7314/APJCP.2014.15.19.8483

[41] Bourdeanu, L., Chen, L. and Luu, T. (2017) RetrospectiveReview for Prevalence and Survival in MetastaticBreast Cancer with Brain Metastasis in Two Patient Cohorts: One Collected 2000-2005 and the Second Collected 2006-2011. Journal of Cancer Therapy, 8, 490-505. https://doi.org/10.4236/jct.2017.85042

[42] Niikura, N., Hayashi, N., Masuda, N., Takashima, S., Nakamura, R., Watanabe, K., et al. (2014) Treatment Outcomes and Prognostic Factors for Patients with Brain Metastases from Breast Cancer of Each Subtype: A Multicenter Retrospective Analysis. Breast Cancer Research and Treatment, 147, 103-112. https://doi.org/10.1007/s10549-014-3090-8

[43] Wadasadawala, T., Gupta, S., Bagul, V. and Patil, N. (2007) Brain Metastases from Breast Cancer: Management Approach. Journal of Cancer Research and Therapeutics, 3, 157-165. https://doi.org/10.4103/0973-1482.37409

[44] Ushio, A., Sawaki, M., Fujia, T., Hattori, M., Kondo, N., Horio, A., Gondou, N., Iwata, H., et al. (2012) Clinicopathological Analysis of Breast Cancer Patients with Brain Metastases. Cancer Research, 72, P3-12-06-P3-12-06. https://doi.org/10.1158/0008-5472.SABCS12-P3-12-06 
[45] Ghersi, D., Wilcken, N., Simes, J. and Donoghue, E. (2005) Taxane Containing Regimens for Metastatic Breast Cancer. Cochrane Database of Systematic Reviews, 2005, CD003366. https://doi.org/10.1002/14651858.CD003366.pub2 